\title{
Spherical cap modelling of Ørsted magnetic field vectors over southern Africa
}

\author{
P. B. Kotzé \\ Hermanus Magnetic Observatory, CSIR, P.O. Box 32, Hermanus 7200, South Africa
}

(Received September 6, 2000; Revised January 31, 2001; Accepted February 6, 2001)

\begin{abstract}
Vector magnetic field observations by the Ørsted satellite during geomagnetic quiet conditions around January 1, 2000, have been employed to derive a spherical cap harmonic model (Haines, 1985) over the southern African region between $10^{\circ}$ and $45^{\circ}$ South in latitude and between $10^{\circ}$ and $45^{\circ}$ East in longitude. In the process a total of 9283 vector (27949 component) Ørsted observations have been used to derive a spherical cap model with minimum wavelength resolution approximately $1200 \mathrm{~km}$. This model is compared with the global Ørsted magnetic field model (Olsen et al., 2000a) in terms of a fit to observatory and repeat station data over the southern African subcontinent where the Hermanus Magnetic Observatory conducts field surveys at regular 5 year intervals.
\end{abstract}

\section{Introduction}

The Ørsted satellite was successfully launched on February 23, 1999 from the Vandenberg Air Force basis in California, almost twenty years after the Magsat mission. Ørsted is located on a low Earth orbit with an inclination of $96.5^{\circ}$, a perigee at $638 \mathrm{~km}$ and an apogee at $849 \mathrm{~km}$. The orbit plane is slowly drifting in local time, from initially $14-02$ hours LT, to 8-20 hours LT at the end of it's planned operational period. The principal objective of the mission is the accurate mapping of the Earth's magnetic field arising from internal sources as well as the characterisation of various current systems.

This paper discusses the modelling of Ørsted vector magnetic field measurements over southern Africa by means of Spherical Cap Harmonic Analysis (SCHA), using quiet time data (Dst less than $\pm 20 \mathrm{nT}$ ) between December 1999 and January 2000. Significant current systems exist within and on the boundary of the magnetosphere, resulting in large magnetic fields described by various magnetic activity indices. Due to its orbit, Ørsted is affected by both polar auroral electrojets as well as field-aligned currents. For this investigation however, we assume that ring currents dominate at the low latitudes considered and that these can be represented by the Dst index.

Regional geomagnetic field models attempt to provide a representation of the Earth's magnetic field over a restricted area. These models are generally able to represent wavelengths shorter than those in global field models, and therefore not only represent sources in the core but also crustal sources. The power spectrum of the geomagnetic field at the Earth's surface is dominated by core fields at wavelengths greater than $3000 \mathrm{~km}$, with crustal fields dominant at shorter wavelengths (Lowes, 1974) as represented by spherical harmonic degree greater than 13, requiring at least 195 model coefficients. Although conventional spherical harmonic

Copy right (C) The Society of Geomagnetism and Earth, Planetary and Space Sciences (SGEPSS); The Seismological Society of Japan; The Volcanological Society of Japan; The Geodetic Society of Japan; The Japanese Society for Planetary Sciences. analysis can be applied to data confined to a limited geographical area, numerical instabilities arise when deriving the model coefficients as the global spherical harmonic functions are not orthogonal over a restricted area.

Haines (1985) showed that Laplace's equation can be solved over a spherical cap, subject to boundary conditions applicable to geomagnetic potential field analysis. According to this method of analysis, the maximum degree of a spherical cap harmonic model, truncated at a certain number of model coefficients, is a function of the half-angle of the spherical cap that determines the minimum wavelength resolution that can be obtained. As the radial distance also enters into the formulation, data over a range of altitudes can be used to derive a model. In the case of a SCHA model far less coefficients are necessary to obtain the same wavelength resolution as in a global spherical harmonic model, eg. in order to obtain a wavelength resolution of approximately 1200 $\mathrm{km}$, would require a spherical harmonic model of degree 33, resulting in 1155 model coefficients, while only 64 SCHA model coefficients would be required to obtain the same result at a half-cap angle of $20^{\circ}$.

\section{Spherical Cap Harmonic Analysis (SCHA)}

SCHA is a mathematical technique developed by Haines (1985) to model a potential field and its spatial derivatives, or a general function and its surface derivatives, on a regional scale in order to overcome the non-orthogonality problem in the case of global spherical harmonic models when applied to restricted areas. Haines and Newitt (1986) used SCHA to derive a regional geomagnetic field model for Canada using Magsat data in addition to other field survey data sets. Similarly, De Santis et al. (1990) and Torta et al. (1993) employed spherical cap techniques to derive regional geomagnetic field models over Italy and Spain respectively, using both Magsat and ground vector data. Recently, Haines and Newitt (1997) used SCHA to model the secular variation and main field simultaneously over Canada, using various data sets that include both vector and scalar observations at 
ground and satellite altitudes. The SCHA modelling technique has also been used successfully to derive a regional field model over southern Africa, using only scalar data from the POGS mission (Kotzé and Barraclough, 1997).

The solution to Laplace's equation over a spherical cap for both internal as well as external sources is given by:

$$
\begin{aligned}
V(r, \theta, \lambda)= & a \sum_{k=0}^{K i n t} \sum_{m=0}^{k}\left(\frac{a}{r}\right)^{n_{k}(m)+1} P_{n_{k}(m)}^{m}(\cos \theta) \\
& *\left[g_{k}^{m, i} \cos (m \lambda)+h_{k}^{m, i} \sin (m \lambda)\right] \\
& +a \sum_{k=1}^{K e x t} \sum_{m=0}^{k}\left(\frac{a}{r}\right)^{n_{k}(m)} P_{n_{k}(m)}^{m}(\cos \theta) \\
& *\left[g_{k}^{m, e} \cos (m \lambda)+h_{k}^{m, e} \sin (m \lambda)\right]
\end{aligned}
$$

where:

$r, \theta, \lambda$ are the geocentric spherical coordinates radius, colatitude, and longitude;

$a=$ reference radius;

$P_{n_{k}(m)}^{m}(\cos \theta)=$ associated Legendre function with integral order $m$ and real degree $n_{k}(m)$;

$k=$ ordering index, with Kint the maximum index for internal sources, and $K$ ext the maximum index for external sources;

$g_{k}^{m, i}, h_{k}^{m, i}, g_{k}^{m, e}, h_{k}^{m, e}$ are the spherical cap coefficients.

If the half-angle of the spherical cap is denoted by $\theta_{o}$, the $n_{k}(m)$ are determined as the roots of the equation, for given $m$ :

$$
d P_{n_{k}(m)}^{m}\left(\cos \theta_{o}\right) / d \theta=0, \quad k-m=\text { even }
$$

and additionally, if differentiability with respect to $\theta$ is required:

$$
d P_{n_{k}(m)}^{m}\left(\cos \theta_{o}\right)=0, \quad k-m=\text { odd } .
$$

If the expansion in Eq. (1) is truncated at $k=K$, the number of model coefficients is $(K+1)^{2}$.

When applying spherical cap harmonic analysis, it is recommended to remove a global spherical harmonic potential from the total potential in order to improve convergence as well as extrapolation beyond the spherical cap boundary (Haines, 1985). In this study the IGRF 2000 model (Olsen et al., 2000b) was subtracted from the Ørsted field component data. The full regional model then consists of the IGRF 2000 model and the SCHA model that describes that part of the field not represented by the IGRF 2000 model.

\section{Selection of Data and Pre-Processing}

Ørsted vector magnetic field measurements over the southern African region covering the area between $10^{\circ} \mathrm{S}$ and $45^{\circ} \mathrm{S}$ in latitude and between $10^{\circ} \mathrm{E}$ and $45^{\circ} \mathrm{E}$ in longitude were selected around January 1, 2000. In particular we selected only quiet time data corresponding to a $D s t$ index between $-20 \mathrm{nT}$ and $+20 \mathrm{nT}$ for both day and night time observations for the period December 1999 till January 2000, averaging around $-10 \mathrm{nT}$. In the process a total of 9283 vector (27949 component) Ørsted observations have been selected. A plot showing these passes over southern Africa can be seen in Fig. 1.
Oersted Observations : Dec. - Jan. 2000 Southern Africa

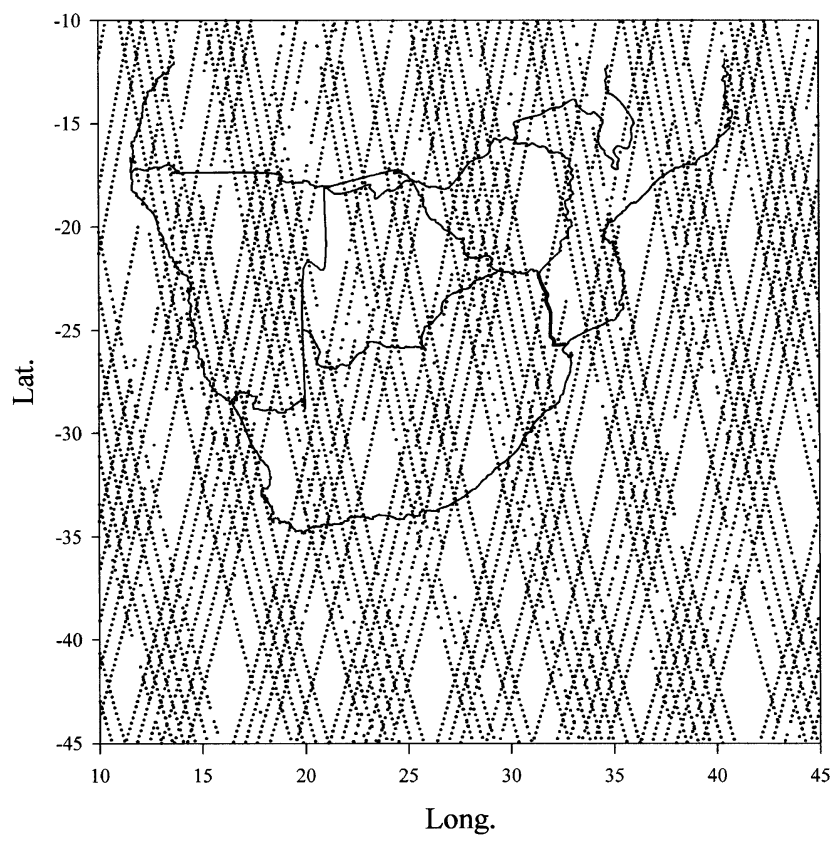

Fig. 1. A plot of Ørsted passes over southern Africa selected during the period December 1999 till January 2000.

Table 1. External field model coefficients.

\begin{tabular}{rrrcrr}
\hline$k$ & $m$ & $n_{k}(m)$ & $K m n$ & \multicolumn{1}{c}{$g_{n k}^{m, e}$} & \multicolumn{1}{c}{$h_{n k}^{m, e}$} \\
\hline 1 & 0 & 6.3834 & $0.100000 \mathrm{E}+01$ & 16.910 & \\
1 & 1 & 4.8433 & $0.376363 \mathrm{E}+01$ & -4.458 & 3.758 \\
2 & 0 & 10.4887 & $0.100000 \mathrm{E}+01$ & 4.816 & \\
2 & 1 & 10.4887 & $0.275299 \mathrm{E}+02$ & 0.337 & -1.189 \\
2 & 2 & 8.3554 & $0.967097 \mathrm{E}+02$ & -1.292 & -1.773 \\
\hline
\end{tabular}

The IGRF 2000 secular variation model (Macmillan and Quinn, 2000) was used to adjust all measurements to the common epoch of 2000.0, corresponding to January 1, 2000 in order to reduce unwanted spurious high degree signals. In order to account for external field effects as a result of ionospheric currents, an external field SCHA model, centred at $27.5^{\circ} \mathrm{S}$ and $27.5^{\circ} \mathrm{E}$, and half-cap angle of $20^{\circ}$ was fitted separately to the complete data set. The external potential was of the form of Eq. (1), with Kext $=2$, and Kint $=0$. Model coefficients obtained are presented in Table 1.

In this table $K m n$ is the Schmidt normalizing constant for the associated Legendre function of order $m$ and real degree $n_{k}(m)$.

This determination yielded $g_{1}^{o, e}=16.9 \mathrm{nT}$, which compares favourably with $g_{1}^{0, e}=20.4 \mathrm{nT}$, obtained by Langel and Estes (1985) when modelling Magsat data, as well as a value of $g_{1}^{0, e}=22.3 \mathrm{nT}$ obtained by Olsen et al. (2000a) while deriving a global spherical harmonic model using Ørsted observations. Previous studies by e.g. Langel and Sweeney (1971) have indicated that the greatest part of external field contributions can be represented by low-degree 
Table 2. Statistically significant internal field spherical cap coefficients.

\begin{tabular}{rrrcrr}
\hline$k$ & $m$ & $n_{k}(m)$ & $K m n$ & \multicolumn{1}{c}{$g_{n k}^{m, i}$} & \multicolumn{1}{c}{$h_{n k}^{m, i}$} \\
\hline 0 & 0 & 0.0000 & $0.100000 \mathrm{E}+01$ & 29.284 & \\
1 & 0 & 6.3834 & $0.100000 \mathrm{E}+01$ & -9.781 & \\
1 & 1 & 4.8433 & $0.376363 \mathrm{E}+01$ & -2.845 & -16.024 \\
2 & 1 & 10.4887 & $0.275299 \mathrm{E}+02$ & -0.276 & -0.706 \\
2 & 2 & 8.3554 & $0.967097 \mathrm{E}+02$ & -1.972 & -2.132 \\
3 & 1 & 14.7934 & $0.383337 \mathrm{E}+02$ & 0.081 & 0.206 \\
3 & 2 & 14.2556 & $0.271316 \mathrm{E}+03$ & 0.954 & 1.031 \\
3 & 3 & 11.6865 & $0.733769 \mathrm{E}+03$ & 2.104 & 1.019 \\
4 & 1 & 19.6048 & $0.504052 \mathrm{E}+02$ & 0.007 & 0.018 \\
4 & 2 & 18.7544 & $0.463084 \mathrm{E}+03$ & -0.512 & -0.554 \\
4 & 3 & 17.8586 & $0.255142 \mathrm{E}+04$ & -1.400 & -0.678 \\
4 & 4 & 14.9334 & $0.566502 \mathrm{E}+04$ & 0.581 & 0.045 \\
5 & 1 & 23.9672 & $0.613485 \mathrm{E}+02$ & -0.030 & -0.076 \\
5 & 2 & 23.6402 & $0.728814 \mathrm{E}+03$ & 0.116 & 0.126 \\
5 & 3 & 22.5349 & $0.506411 \mathrm{E}+04$ & 1.252 & 0.607 \\
5 & 4 & 21.3613 & $0.233316 \mathrm{E}+05$ & 0.742 & 0.058 \\
5 & 5 & 18.1299 & $0.441154 \mathrm{E}+05$ & -6.760 & 2.058 \\
6 & 1 & 28.6499 & $0.730941 \mathrm{E}+02$ & 0.016 & 0.042 \\
6 & 2 & 28.0892 & $0.102284 \mathrm{E}+04$ & 0.065 & 0.070 \\
6 & 3 & 27.5164 & $0.913581 \mathrm{E}+04$ & -0.500 & -0.242 \\
6 & 4 & 26.1999 & $0.522975 \mathrm{E}+05$ & -1.853 & -0.144 \\
6 & 5 & 24.7947 & $0.209358 \mathrm{E}+06$ & 1.479 & -0.450 \\
6 & 6 & 21.2921 & $0.345220 \mathrm{E}+06$ & 14.487 & -11.448 \\
7 & 1 & 33.0442 & $0.841161 \mathrm{E}+02$ & -0.003 & -0.008 \\
7 & 2 & 32.8077 & $0.138889 \mathrm{E}+04$ & -0.070 & -0.075 \\
7 & 3 & 32.0551 & $0.143549 \mathrm{E}+05$ & 0.019 & 0.009 \\
7 & 4 & 31.2822 & $0.105458 \mathrm{E}+06$ & 1.052 & 0.082 \\
7 & 5 & 29.7830 & $0.520060 \mathrm{E}+06$ & 1.703 & -0.518 \\
7 & 6 & 28.1768 & $0.185274 \mathrm{E}+07$ & -4.545 & 3.591 \\
7 & 7 & 24.4291 & $0.270954 \mathrm{E}+07$ & -1.178 & 1.111 \\
\hline & & & & & \\
\hline
\end{tabular}

terms. Using these coefficients, a value for the external field contribution was calculated for every vector component at each measurement position. Prior to removing the core field contribution from all observations by means of the IGRF 2000 model, we subtracted this modelled external field.

\section{SCHA Model and Comparison with Field Sur- vey Data}

The resulting residual data were converted from a geocentric coordinate system to a new pole at $27.5^{\circ} \mathrm{S}, 27.5^{\circ} \mathrm{E}$. The nonintegral degrees $n_{k}(m)$ for the spherical cap are determined as the roots of Eqs. (2) and (3), each considered as an equation in $n$ at given $m$ and $\theta_{o}$, using an iterative scheme of successive bisection and inverse parabolic interpolation. The internal field model was restricted to $K i n t=7$, and a half-cap angle of $20^{\circ}$, resulting in a minimum wavelength resolution of approximately $1200 \mathrm{~km}$. A stepwise multiple regression procedure, based on the algorithm of Efroymson (1960) allowed the determination of the Gaussian coeffi-
Difference : Field Survey - Model

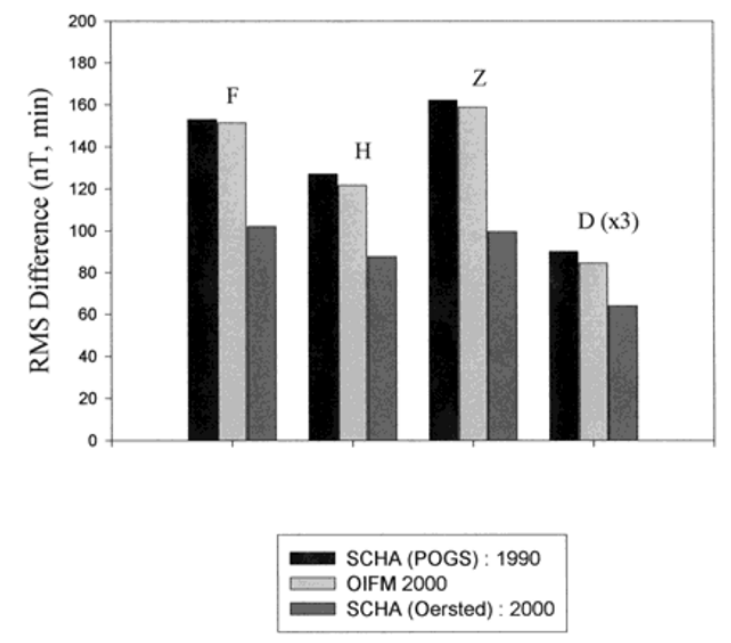

Fig. 2. Comparison of RMS differences between 2000.0 field survey data and the OIFM 2000 model, and on the other hand, the 2000.0 field observations and the SCHA 2000 model. For comparative purposes the RMS differences between the 1990 field survey data and the POGS-based SCHA 1990 model are also displayed.

cients. Of the possible 64 coefficients in our spherical cap model of maximum index 7 , a total of 59 were significant at an $F$ level of 3, as presented in Table 2. These coefficients correspond to a SCHA expansion in Eq. (1), limited to only the internal field potential, and with no temporal dependence.

The total RMS misfit between the satellite data and this SCHA model amounts to 4.1 arc minutes for $D, 16.6 \mathrm{nT}$ for $F, 22.7 \mathrm{nT}$ for the horizontal component $H$, and $17.9 \mathrm{nT}$ for the vertical field component $Z$.

A comparison between the southern African field survey data obtained at 68 stations, including the Hermanus, Hartebeesthoek and Tsumeb observatories, and the OIFM 2000 and our SCHA 2000 model based also only on Ørsted measurements, can be seen in Fig. 2. For comparative purposes we also show the RMS differences obtained between the 1990 field observations and the POGS-based SCHA model. The SCHA model based on POGS scalar data, compares favourably with the global OIFM 2000 model, but is clearly inferior to the SCHA model based on Ørsted vector measurements. It is also clear that the SCHA 2000 model provides a significant improvement (in some cases up to 30\%) to the fit of the OIFM 2000 model to the ground data over southern Africa. Contour maps of $F, H, D$, and $Z$ components of the regional geomagnetic field as computed by the SCHA 2000 model are shown in Figs. 3, 4, 5, and 6 respectively.

\section{Discussion}

Although no ground magnetic field data have been incorporated in deriving the spherical cap harmonic regional field model over southern Africa, SCHA 2000 provides a significant improvement to the OIFM 2000 global field model when compared to 2000.0 field survey data. It is also clear that this SCHA model based on vector observations is a 


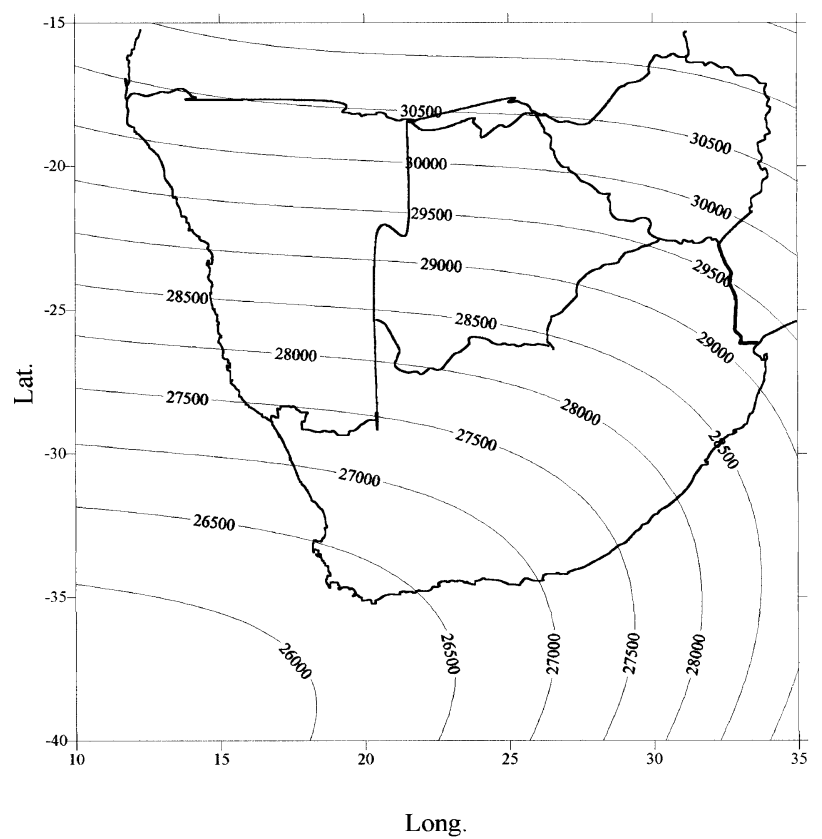

Fig. 3. A contour plot of total field $F$ for epoch 2000.0 at sea level over southern Africa as derived from the SCHA 2000 model at an interval of $500 \mathrm{nT}$.

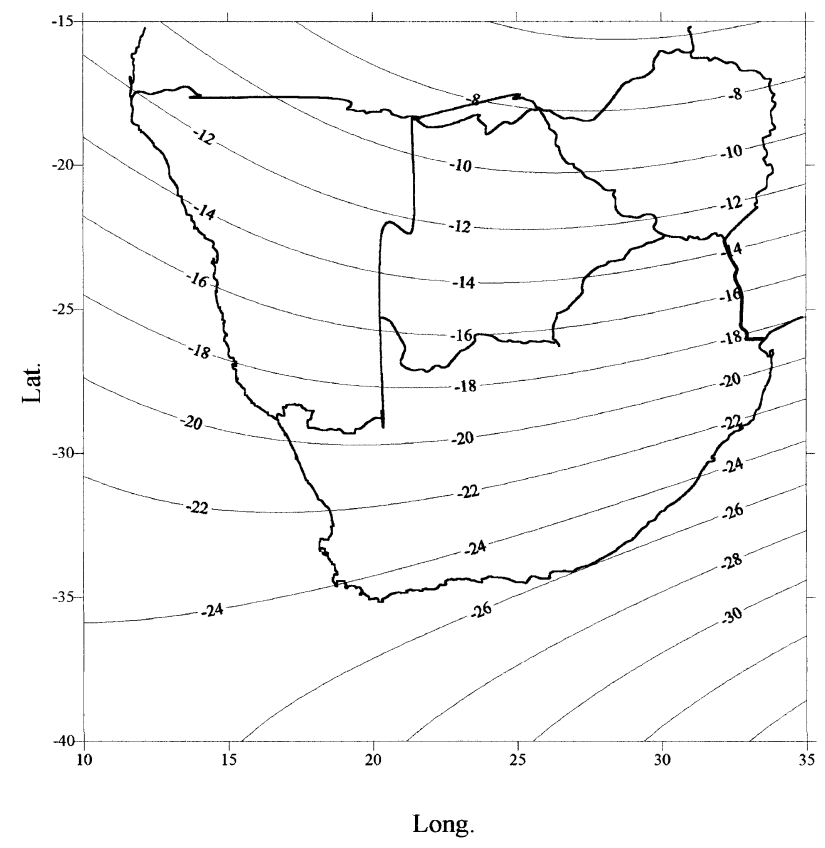

Fig. 5. A contour plot of declination $D$ as calculated by means of the Ørsted-based SCHA 2000 field model at sea level for epoch 2000.0 over the southern African region. Contour interval is $2^{\circ}$.

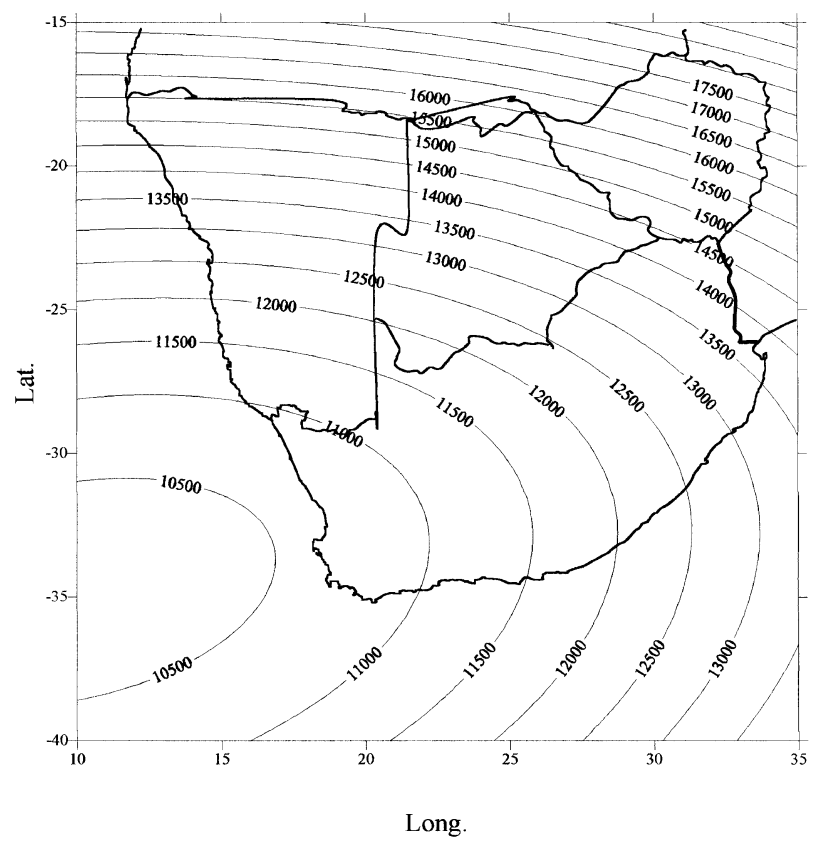

Fig. 4. Contour plot of the horizontal component $H$ for epoch 2000.0 at sea level as computed by means of the SCHA 2000 model with a contour interval of $500 \mathrm{nT}$.
SCHA : Z (nT) : 2000.0

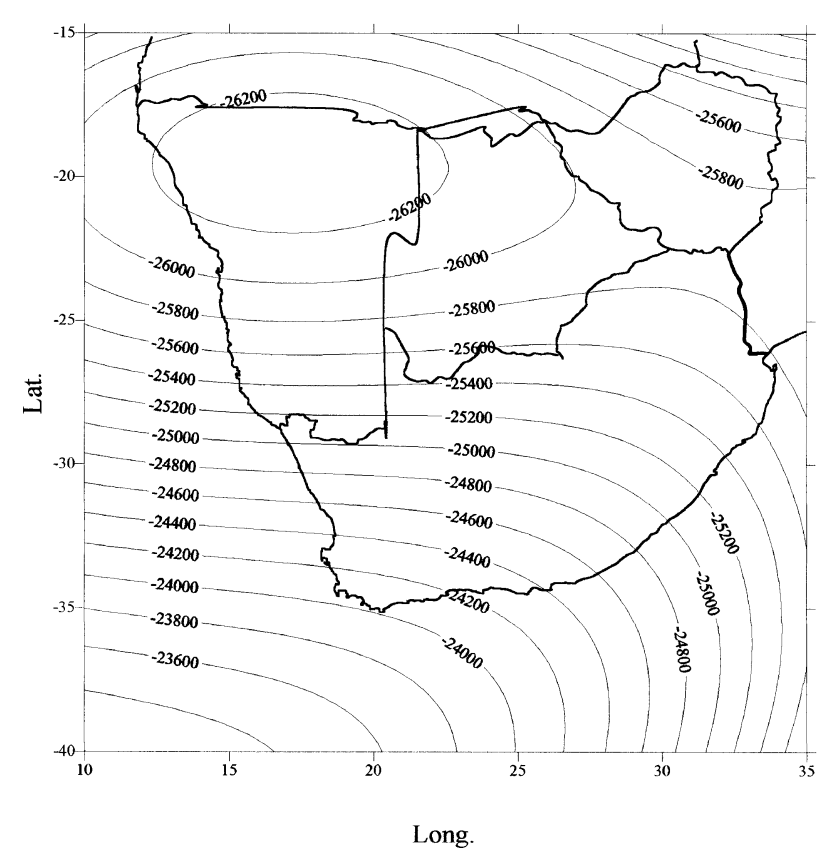

Fig. 6. A contour plot of the vertical field component $Z$ as derived from the SCHA 2000 field model at sea level for epoch 2000.0 over southern Africa. Contour interval is $200 \mathrm{nT}$. 
better approximation to field measurements than the SCHA model derived from scalar POGS data. The contour maps produced from this regional model are in good agreement with charts derived using a 3rd degree polynomial model, based on only field survey data, over the land areas, but over the ocean areas, the SCHA 2000 model is by far superior. This investigation has shown that a regional field model is in many aspects superior to a global field model. In this case both the OIFM 2000 as well as the SCHA 2000 model are based only on Ørsted magnetic field observations. Inclusion of ground field survey data may provide a better extrapolation of satellite data to the Earth's surface. This will be considered when deriving the final regional geomagnetic field for the southern African region, especially towards the borders of the cap where the model is most sensitive to the lack of ground data.

Acknowledgments. We are grateful for the support of the Ørsted Project Office and the Ørsted Science Data Centre at the Danish Meteorological Institute. The Ørsted Project is funded by the Danish Ministry of Trade and Industry, with additional support provided by the National Aeronautics and Space Administration (NASA), European Space Agency (ESA), Centre Nationale d'Etudes Spatiale (CNES), and the Deutsche Agentur für Raumfahrtangelegenheiten (DARA). Useful comments given by $M$. Purucker and Y. Nishida when evaluating this paper, are gratefully acknowledged.

\section{References}

De Santis, A., O. Battelli, and D. J. Kerridge, Spherical cap harmonic analysis applied to regional field modelling for Italy, J. Geomag. Geoelectr.,
42, 1019-1036, 1990.

Efroymson, M. A., Multiple regression analysis, in Mathematical Methods for Digital Computers, edited by A. Ralston and H. S. Wilf, pp. 191-203, John Wiley \& Sons, New York, 1960.

Haines, G. V., Spherical cap harmonic analysis, J. Geophys. Res., 90, 2583$2592,1985$.

Haines, G. V. and L. R. Newitt, Canadian geomagnetic reference field, $J$. Geomag. Geoelectr., 38, 895-921, 1986.

Haines, G. V. and L. R. Newitt, The Canadian geomagnetic reference field 1995, J. Geomag. Geoelectr., 49, 317-336, 1997.

Kotzé, P. B. and D. R. Barraclough, Modelling and analysis of POGS data over Southern Africa by spherical cap harmonic analysis, J. Geomag. Geoelectr., 49, 441-452, 1997.

Langel, R. A. and R. H. Estes, Large-scale near-Earth magnetic fields from external sources and the corresponding induced internal field, $J$. Geophys. Res., 90, 2487-2494, 1985.

Langel, R. A. and R. E. Sweeney, Asymmetric ring current at twilight local time, J. Geophys. Res., 76, 4420-4427, 1971.

Lowes, F. J., Spatial spectrum of the main geomagnetic field and extrapolation to the core, Geophys. J. R. Astron. Soc., 36, 717-730, 1974.

Macmillan, S. and J. M. Quinn, The 2000 revision of the joint UK/US geomagnetic field models and an IGRF 2000 candidate model, Earth Planets Space, 52, 1149-1162, 2000.

Olsen, N., R. Holme, G. Hulot, T. Sabaka, T. Neubert, L. Tøffner-Clausen, F. Primdahl, J. Jørgensen, J.-M. Léger, D. Barraclough, J. Bloxham, J. Cain, C. Constable, V. Golovkov, A. Jackson, P. Kotzé, B. Langlais, S. Macmillan, M. Mandea, J. Merayo, L. Newitt, M. Purucker, T. Risbo, M. Stampe, A. Thomson, and C. Voorhies, Ørsted initial field model, Geophys. Res. Lett., 27, 3607-3610, 2000a.

Olsen, N., T. J. Sabaka, and L. Tøffner-Clausen, Determination of the IGRF 2000 model, Earth Planets Space, 52, 1175-1182, 2000b.

Torta, J. M., A. Garcia, and A. de Santis, A geomagnetic reference field for Spain at 1990, J. Geomag. Geoelectr., 45, 573-588, 1993.

P. B. Kotzé (e-mail: pkotze@csir.co.za) 